\title{
Ice-shelf flexure and tidal forcing of Bindschadler Ice Stream, West Antarctica
}

\author{
Ryan T. Walker ${ }^{\mathrm{a}, \mathrm{e}, *}$, Byron R. Parizek ${ }^{\mathrm{b}}$, Richard B. Alley ${ }^{\mathrm{c}}$, Kelly M. Brunt ${ }^{\mathrm{d}, \mathrm{e}}$, \\ Sridhar Anandakrishnan ${ }^{\mathrm{C}}$ \\ a Earth System Science Interdisciplinary Center, University of Maryland, College Park, MD 20742, USA \\ ${ }^{\mathrm{b}}$ Mathematics and Geoscience, 181 Smeal Building, Penn State DuBois, College Place, DuBois, PA 15801, USA \\ c Department of Geosciences, 517 Deike Building, Pennsylvania State University, University Park, PA 16802, USA \\ ${ }^{\mathrm{d}}$ Goddard Earth Sciences Technology and Research (GESTAR), USA \\ e Cryospheric Sciences Laboratory, Mail Code 615, NASA Goddard Space Flight Center, 8800 Greenbelt Road, Greenbelt, MD 20771, USA
}

\section{A R T I C L E I N F O}

\section{Article history:}

Received 25 November 2013

Received in revised form 28 February 2014

Accepted 22 March 2014

Available online $\mathrm{xxxx}$

Editor: J. Lynch-Stieglitz

\section{Keywords:}

ice shelf

ice stream

ocean tides

viscoelastic

\begin{abstract}
A B S T R A C T
Viscoelastic models of ice-shelf flexure and ice-stream velocity perturbations are combined into a single efficient flowline model to study tidal forcing of grounded ice. The magnitude and timing of icestream response to tidally driven changes in hydrostatic pressure and/or basal drag are found to depend significantly on bed rheology, with only a perfectly plastic bed allowing instantaneous velocity response at the grounding line. The model can reasonably reproduce GPS observations near the grounding zone of Bindschadler Ice Stream (formerly Ice Stream D) on semidiurnal time scales; however, other forcings such as tidally driven ice-shelf slope transverse to the flowline and flexurally driven till deformation must also be considered if diurnal motion is to be matched.
\end{abstract}

(c) 2014 Elsevier B.V. All rights reserved.

\section{Introduction}

The influence of ocean tides on ice shelves and their tributary ice streams provides opportunities for investigation of fundamental processes controlling flow at ice-sheet margins. Early observational (Robin, 1958) and theoretical (Holdsworth, 1969, $1977,1981)$ studies of vertical ice-shelf flexure led to more complex modeling studies (Schmeltz et al., 2002; Reeh et al., 2003; Sergienko, 2010; Sayag and Worster, 2011, 2013), and ultimately to the use of remote sensing to detect the grounding zone over which ice transitions between grounded and freely floating states (Scambos et al., 2007; Fricker et al., 2009; Brunt et al., 2010, 2011; Bindschadler et al., 2011; Rignot et al., 2011). Meanwhile, GPS observations demonstrated that the flow of several Siple Coast ice streams into the Ross Ice Shelf (Anandakrishnan et al., 2003; Bindschadler et al., 2003; Winberry et al., 2009, 2011) and the flow of Rutford Ice Stream into the Ronne Ice Shelf (Gudmundsson, 2006, 2007; Murray et al., 2007; King et al., 2010) are modulated by the tides. Modeling studies of these velocity perturbations

\footnotetext{
* Corresponding author at: Cryospheric Sciences Laboratory, Mail Code 615, NASA Goddard Space Flight Center, 8800 Greenbelt Road, Greenbelt, MD 20771, USA. Tel.: +1 3016146933 .

E-mail address: ryan.t.walker@nasa.gov (R.T. Walker).
}

suggest that the ice-stream beds can have markedly different characteristics, with Gudmundsson (2011) finding a basal flow law for Rutford Ice Stream consistent with hard-bed sliding or lowstress-exponent till deformation while Walker et al. (2012) find an effectively plastic basal flow law for Bindschadler Ice Stream (on the Siple Coast) consistent with sliding over weakly velocitystrengthening till (Tulaczyk, 2006).

The precise mechanisms by which tidal motion causes modulation of ice-stream flow are not yet well known, but it is likely that improved understanding of these mechanisms will provide insight to grounding-zone processes that affect ice-stream dynamics. The two most obvious processes are the change in hydrostatic pressure with tidal height and transient changes in grounding due to flexure, although modeling of the latter in an elastic, non-hydrostatic manner remains an active area of research (e.g., Sayag and Worster, 2011, 2013). Other potentially significant processes include changes in ice-shelf slope due to spatially nonuniform tides (Brunt, 2008), flexurally induced variation in subglacial pressure affecting water flow (Walker et al., 2013), and formation of "sticky spots" due to repeated vertical compaction of till (Christianson et al., 2013). Anandakrishnan and Alley (1997) were able to explain tidally forced basal seismicity of ice stream C (now Kamb Ice Stream) using a simplified model of an elastic ice stream with no explicit shelf overlying a viscous 
bed. More recently, Gudmundsson (2011) used a viscoelastic, fullStokes model to show that the fortnightly modulation of Rutford Ice Stream can be explained by interaction between semidiurnal tidal constituents provided that the basal sliding law is nonlinear.

In this study, we combine and expand earlier models of iceshelf flexure (Walker et al., 2013) and ice-stream response to stress perturbations (Walker et al., 2012) to analyze how tidal forcing leads to modulation of ice-stream flow, with an emphasis on velocity perturbations in the grounding zone. Beginning with experiments on idealized domains, we demonstrate the importance of basal rheology in determining the magnitude and timing of the response to a given forcing. The model is then applied to Bindschadler Ice Stream, resulting in broad agreement with the observations of Anandakrishnan et al. (2003).

\section{Model derivation}

The vertical displacement $w$ of the ice shelf/stream (at time $t(\mathrm{~s})$ at a horizontal position $x(\mathrm{~m})$ along a chosen flowline) is calculated from the model of Walker et al. (2013),

$\partial_{t}\left(k w+\partial_{x}^{2}\left(D \partial_{x}^{2} w\right)\right)+\frac{E k}{2 v\left(1-\lambda^{2}\right)} w=\partial_{t} q+\frac{E}{2 v\left(1-\lambda^{2}\right)} q$,

which represents the ice as a viscoelastic beam with Young's modulus $E$, viscosity $\nu$, and Poisson's ratio $\lambda$ resting (where grounded) on an elastic foundation with spring constant $k$. The flexural rigidity of the ice is given by

$D \equiv \frac{E h^{3}}{12\left(1-\lambda^{2}\right)}$,

where the thickness $h$ can vary along flow. Hydrostatic pressure provides an applied load,

$q=\rho_{w} g(\eta-w)$,

wherever the vertical displacement of the shelf differs from the tidal height $\eta$. The vertical displacement calculated by the flexural model comprises part of the forcing of the flowline model described below.

To derive the perturbed flowline model (following Walker et al. (2012)), we first remove the assumption of viscous rheology from the Dupont and Alley (2005) momentum equation to obtain

$\partial_{x}\left(2 h \sigma-\frac{1}{2} \rho g h^{2}\right)=P_{b} \partial_{x} b+\tau_{b}(u)$,

where $u$ is velocity and $\sigma$ is along-flow deviatoric stress. The along-flow component of basal pressure $P_{b} \partial_{x} b$ (which results from depth-integration) is the product of the pressure $P_{b}$ (cryostatic or hydrostatic) and slope at the bottom surface of the ice, while the basal drag under grounded ice is given by the power-law bed rheology $\tau_{b}(u)=\beta^{2} u^{\frac{1}{m}}$, which can range from linear viscous $(m=1)$ to perfectly plastic $(m \rightarrow \infty)$ with the drag coefficient $\beta^{2}(x, t)$ typically determined empirically. If we then consider small changes in velocity and stress, the perturbed momentum equation is

$\partial_{x}\left(2 h(\sigma+\tilde{\sigma})-\frac{1}{2} \rho g h^{2}\right)=P_{b} \partial_{x} b+\tau_{b}(u+\tilde{u})$,

where $\tilde{\sigma}, \tilde{u}$ are the perturbation stress and velocity and $\sigma, u$ are the background state (derived from observations and/or standard viscous ice-flow modeling as in Walker et al. (2012)). Assuming negligible change in ice thickness or background state over the relatively short (on the order of days) timescales of interest, differentiating with respect to time gives

$\partial_{x}\left(2 h \partial_{t} \tilde{\sigma}\right)=\partial_{t}\left(P_{b} \partial_{x} b\right)+\partial_{t}\left(\tau_{b}(u+\tilde{u})\right)$.
In Walker et al. (2012), which was concerned only with grounded ice, it was assumed that neither the basal pressure $P_{b} \partial_{x} b$ nor the basal drag coefficient $\beta^{2}$ varied in time; however, this assumption is no longer valid when vertical flexure of the ice shelf and/or tidally-driven changes in grounding are considered. For the basal drag term, we now have

$\partial_{t} \tau_{b}=\partial_{t}\left(\beta^{2}(u+\tilde{u})^{\frac{1}{m}}\right)=\frac{\beta^{2}}{m}(u+\tilde{u})^{\frac{1}{m}-1} \partial_{t} \tilde{u}+\partial_{t}\left(\beta^{2}\right)(u+\tilde{u})^{\frac{1}{m}}$,

which adds a term to the earlier model. As for the basal pressure, the elevation of the base of an ice shelf subject to tidal flexure is $z=b(x, t)=z_{b}(x)+w(x, t)$, and its depth is $\eta(x, t)-b=\eta-z_{b}-w$, where $\eta$ is the tidal height, $w$ is the vertical flexure of the shelf (calculated from (1)), and $z_{b}$ is the initial basal elevation when $\eta=$ $w=0$. We define $z=0$ at sea level (i.e., the sea surface elevation when $\eta=0$ ). Assuming hydrostatic pressure at the ice-shelf base and using the preceding expressions for basal depth and elevation leads to

$P_{b} \partial_{x} b=\rho_{w} g\left(\eta-z_{b}-w\right) \partial_{x}\left(z_{b}+w\right)$,

so that

$\partial_{t}\left(P_{b} \partial_{x} b\right)=\rho_{w} g\left\{\partial_{t}(\eta-w) \partial_{x}\left(z_{b}+w\right)+\left(\eta-z_{b}-w\right) \partial_{x} \partial_{t} w\right\}$.

As in the earlier model, this term remains zero for grounded ice.

We continue to take ice to be a Maxwell material, the simplest viscoelastic rheology that displays both instantaneous elastic response and long-time viscous behavior. This can be thought of as a spring and dashpot in series, so that the same stress acts across each element and the total strain $\epsilon$ is the sum of the elastic and viscous strains, leading to the differential equation

$\dot{\sigma}=E \dot{\epsilon}-\frac{E}{2 v} \sigma=E \partial_{x} u-\frac{E}{2 v} \sigma$,

(e.g., Turcotte and Schubert, 2002) where E is Young's modulus and the viscosity $v$, given by Glen's flow law, is assumed to change sufficiently slowly that the viscosity of the background state can be used in calculating the perturbations. The final perturbed momentum equation is obtained by substituting (7), (9), and (10) into (6):

$$
\begin{aligned}
\partial_{x}\left(2 h E\left\{\partial_{x} \tilde{u}-\frac{\tilde{\sigma}}{2 v}\right\}\right) \\
=\rho_{w} g\left\{\partial_{t}(\eta-w) \partial_{x}\left(\eta-z_{b}-w\right)\right. \\
\left.\quad+\left(\eta-z_{b}-w\right) \partial_{x} \partial_{t}(\eta-w)\right\} \\
\quad+\frac{\beta^{2}}{m}(u+\tilde{u})^{\frac{1}{m}-1} \partial_{t} \tilde{u}+\partial_{t}\left(\beta^{2}\right)(u+\tilde{u})^{\frac{1}{m}},
\end{aligned}
$$

where advective terms from the total time derivative in (10) are negligible.

We discretize and solve (1) and (11) by the finite element method with fully implicit time differencing, using Hermite cubic and linear elements, respectively. For all experiments in this study, model resolution is $200 \mathrm{~m}$ in $x$ and $600 \mathrm{~s}$ in $t$.

\section{Idealized experiments}

Our idealized flowline is $200 \mathrm{~km}$ long, consisting of a $150 \mathrm{~km}$ ice stream and a $50 \mathrm{~km}$ ice shelf. (As will be seen below, a longer shelf is not necessary for the simple experiments of this section.) The ice stream has a uniform thickness of $500 \mathrm{~m}$, with the shelf tapering linearly to $400 \mathrm{~m}$ at the ice front. Experiments in which the shelf instead tapers following a concave ice-tongue profile 


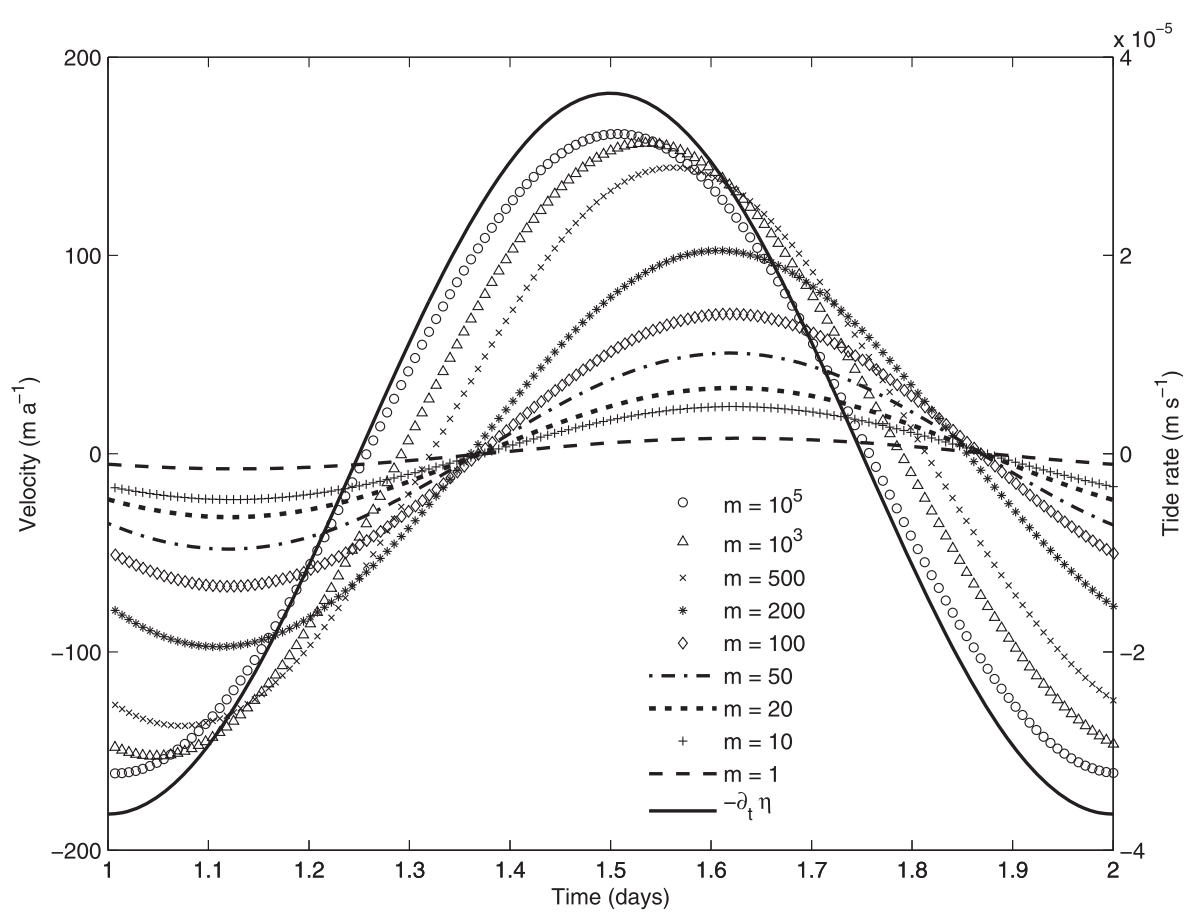

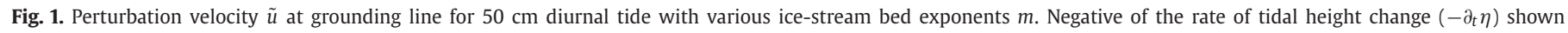
for comparison of timing.

(Holland et al., 2008), leading to lower rigidity, produce negligible differences in vertical flexure $(\sim 1 \mathrm{~mm}$ for $50 \mathrm{~cm}$ tide). The icestream bed has a spring constant $k$ of $10^{7} \mathrm{~Pa} \mathrm{~m}^{-1}$, roughly in the middle of the reasonable range derived in Walker et al. (2013) using C. Marone's unpublished data from experiments in Rathbun et al. (2008). The ice has Young's modulus $E$ either 3.0 or $4.8 \mathrm{GPa}$ and Poisson's ratio $\lambda$ of 0.4 (Anandakrishnan and Alley, 1997; Gudmundsson, 2011). For most of our experiments in this section, the ice will have viscosity $v=10^{20}$ Pas, a deliberately high value chosen to make elastic behavior dominant. The steady-state background velocity $u$ increases linearly from $350 \mathrm{ma}^{-1}$ at the upstream end of the ice stream to $500 \mathrm{ma}^{-1}$ at the grounding line, and the drag coefficient $\beta^{2}$ is set for each exponent $m$ so that the steady-state basal drag (calculated from the power-law bed rheology) decreases linearly from $50 \mathrm{kPa}$ upstream to $20 \mathrm{kPa}$ at the grounding line. We note that the latter value is likely on the high side for a grounding zone, making our idealized configuration rather sensitive to grounding-line motion.

\subsection{Tidal forcing with fixed grounding line}

In order to consider only the effects of hydrostatic pressure (i.e., the term given by (9)), we run these experiments with $w=0$ imposed at a fixed grounding line. The remaining boundary conditions are $w=\partial_{x} w=0$ at the upstream end and $w=\eta(t)$ at the downstream end; the initial conditions are $w=\eta=0$ everywhere. For a diurnal tide with $50 \mathrm{~cm}$ amplitude, shelves with $E=3.0$ and $4.8 \mathrm{GPa}$ both have maximum vertical displacement $w=52.2 \mathrm{~cm}$ at high tide, with the stiffer $(4.8 \mathrm{GPa})$ shelf having a somewhat longer flexure zone (11.0 vs. $9.8 \mathrm{~km}$ until $|w-\eta|<$ $1 \mathrm{~mm}$ ). We note that flexure exceeding the boundary condition on vertical displacement (here, the tidal height) is common in beambending problems; cf. formation of forebulges during flexure of lithospheric plates.

It might be expected that spreading the hydrostatic pressure change due to the difference between vertical flexure and tidal height over a wider grounding zone, thus decreasing the pressure gradient, would produce less forcing on the grounded ice. However, the forcing is dominated by the hydrostatic pressure change at the grounding line, and thus the flexural parameters and the resulting shape of the flexure zone have negligible effect on the force felt by the grounded ice when the grounding line remains stationary. We note that these parameters do become important when tidally driven grounding-line motion is calculated (e.g., Sayag and Worster, 2011, 2013), and that Young's modulus of the grounded ice is a leading control on the magnitude of the velocity perturbation resulting from a given tidal forcing. Also, ice-shelf slope due to spatially varying tides can become significant when considering more realistic scenarios; this effect will be discussed later, when the model is applied to Bindschadler Ice Stream.

The velocity perturbation at the grounding line resulting from a $50 \mathrm{~cm}$ diurnal tide is shown in Fig. 1 for $E=4.8 \mathrm{GPa}$ and bed rheologies ranging from linear $(m=1)$ to perfectly plastic $(m \rightarrow \infty)$. We note that because the ice is in a high-viscosity, elastic-dominated regime, the velocity is linear in Young's modulus, so the $E=3.0 \mathrm{GPa}$ response is 1.6 times larger though identical in timing.

The case of a perfectly plastic bed, while unrealistic, is a useful starting point for understanding the model's behavior. As $m \rightarrow \infty$ (effectively, when $m \gtrsim 10^{5}$ ), the second term on the RHS of (11) is eliminated, taking with it any effect of $\tilde{u}$ on basal drag. (The third RHS term is also zero, as in this case we are not considering variation of the drag coefficient $\beta^{2}$ due to grounding-line motion or basal hydrology.) With the perturbation stress term $\tilde{\sigma} / 2 v$ negligible due to high viscosity, (11) reduces to a Poisson equation in $\tilde{u}$ with time-dependent forcing. The solution is a perturbation velocity profile (linear in this case, as $h$ is constant for the ice stream) in which all points respond instantly to the forcing. Thus, $\tilde{u}$ at the grounding line is $180^{\circ}$ out of phase with the time derivative of the tide, $\partial_{t} \eta$ (i.e., perfectly in phase with $-\partial_{t} \eta$ ). This result is to be expected, because for the grounded ice this simplified case is equivalent to applying a periodic load to an elastic body, for which displacement is linear in stress and velocity linear in stress rate. We note that this dependence of perturbation velocity 


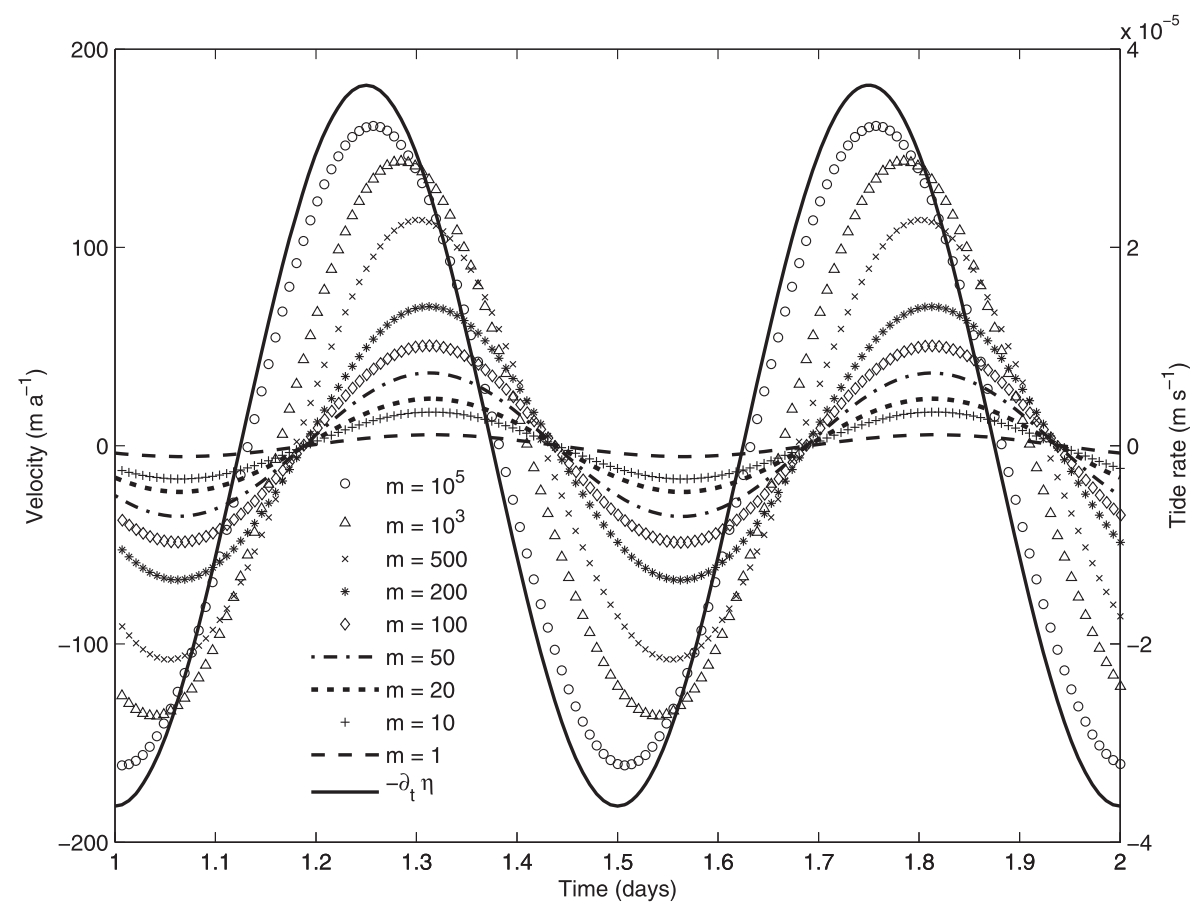

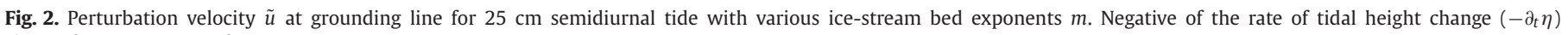
shown for comparison of timing.

on the rate of applied stress strongly affects the magnitude as well as the timing of ice-stream response, with higher-frequency tidal constituents having a stronger effect than their amplitudes alone would suggest. For example, a semidiurnal tide (such as S2, $12.00 \mathrm{~h}$ period) will produce a stress rate and resulting velocity perturbation of comparable magnitude to a diurnal tide (such as K1, $23.93 \mathrm{~h}$ period) with twice the amplitude (Fig. 2).

As $m$ decreases and the ice-stream bed becomes less than perfectly plastic, the basal drag-velocity feedback takes effect, and (11) becomes a nonlinear diffusion equation with time-dependent forcing. Even at the grounding line, the ice stream no longer responds instantly to the rate of tidal height change. For a linear viscous bed $(m=1), \tilde{u}$ lags $-\partial_{t} \eta$ by $3 \mathrm{~h}$ for a diurnal tide. This lag scales with the tidal period (e.g., $1.5 \mathrm{~h}$ for a semidiurnal tide), representing a phase delay of $45^{\circ}$. (For convenience, our diurnal tide in these experiments has a period of exactly $24 \mathrm{~h}$.) As $-\partial_{t} \eta$ is always $90^{\circ}$ behind $\eta$ for a sinusoidal tide, the lag between tidal extrema and the corresponding velocity extrema is $3 / 8$ of the tidal period. The lag changes relatively little as $m$ increases, shortening by only $\sim 10$ min for a diurnal tide when $m=100$. Thus, for most realistic values of $m$, including the range $(m \in[8,40])$ of "effectively plastic" values that Walker et al. (2012) found reasonable for Bindschadler Ice Stream, the bed rheology affects the magnitude but not the timing of the response of an elastic ice stream to tidal forcing.

\subsubsection{Effects of viscosity}

From the Maxwell rheology (10), the viscous and elastic contributions to the strain rate $\partial_{x} \tilde{u}$ are equal when $\sigma / \dot{\sigma}=2 v / E$, that is, when the time scale of the forcing equals the Maxwell relaxation time of the material. Forcing on much shorter time scales produces elastic behavior, and forcing on much longer time scales produces viscous behavior. With $E=4.8 \mathrm{GPa}$ and $\nu=10^{20} \mathrm{Pas}$, the relaxation time is over 1300 years, confirming that the ice stream in our experiments thus far is in the elastic regime. In order to reduce the relaxation time to a day, the depth-averaged effective viscosity must decrease to approximately $2 \times 10^{14} \mathrm{Pas}$, a low but reasonable value for an ice shelf (Brunt, 2008).
We re-run the diurnal tide experiment ( $E=4.8 \mathrm{GPa})$ with a perfectly plastic bed, so that any delay in ice-stream response is due solely to the effect of viscosity. In order to apply consistent forcing, the original (elastic) flexure results are used for all experiments, and only the flowline model is re-run. Results are shown in Fig. 3. For $v \geqslant 10^{16}$ Pas, the results are only negligibly different from the elastic case, and for $v=10^{15}$ Pas only a slight delay ( $\leqslant 10 \mathrm{~min}$ ) is noticeable. A larger delay ( $\sim 20 \mathrm{~min}$ ) occurs for $v=10^{14.5} \mathrm{Pas}$, though the peak velocity due to the viscous contribution remains low enough $\left(\sim 16 \mathrm{ma}^{-1}\right)$ that the overall velocity does not noticeably increase. (Note that the strain rate, and thus the velocity, of a Maxwell material is the sum of viscous and elastic components, so that we can find the viscous contribution to each run by subtracting our earlier elastic results.) As the viscosity drops further, to $v=10^{14}$ Pas, viscous effects become more readily apparent. The peak velocity due to the viscous contribution increases to $\sim 51 \mathrm{ma}^{-1}$, increasing the overall peak velocity by $6.0 \mathrm{ma}^{-1}$, while the delay increases to $70 \mathrm{~min}$. For $v=10^{13.5}$ Pas, the viscous contribution $\left(\sim 157 \mathrm{ma}^{-1}\right)$ becomes comparable to the elastic contribution, increasing the overall peak velocity to $221 \mathrm{ma}^{-1}$ and causing a lag of $3.0 \mathrm{~h}$ behind the elastic case. When $v$ is reduced to $10^{12} \mathrm{Pas}$, viscous effects dominate, leading to a peak velocity over $2100 \mathrm{ma}^{-1}$ offset by $6.0 \mathrm{~h}$ from the elastic case (not shown due to vertical scale). This timing indicates that the icestream response is synchronous with the applied stress, consistent with purely viscous behavior. However, the velocity is unrealistically high when compared with observations (e.g., over an order of magnitude greater than seen by Anandakrishnan et al. (2003) at Bindschadler Ice Stream), even considering the also unrealistic assumption of a perfectly plastic bed. For most reasonable values of viscosity, we expect primarily elastic ice-stream response, with the possibility of a relatively small but noticeable viscous contribution.

\subsection{Grounding-line motion without tides}

To examine the effect of the basal drag terms (7) in isolation, we run experiments in which there is no tide, but grounding- 


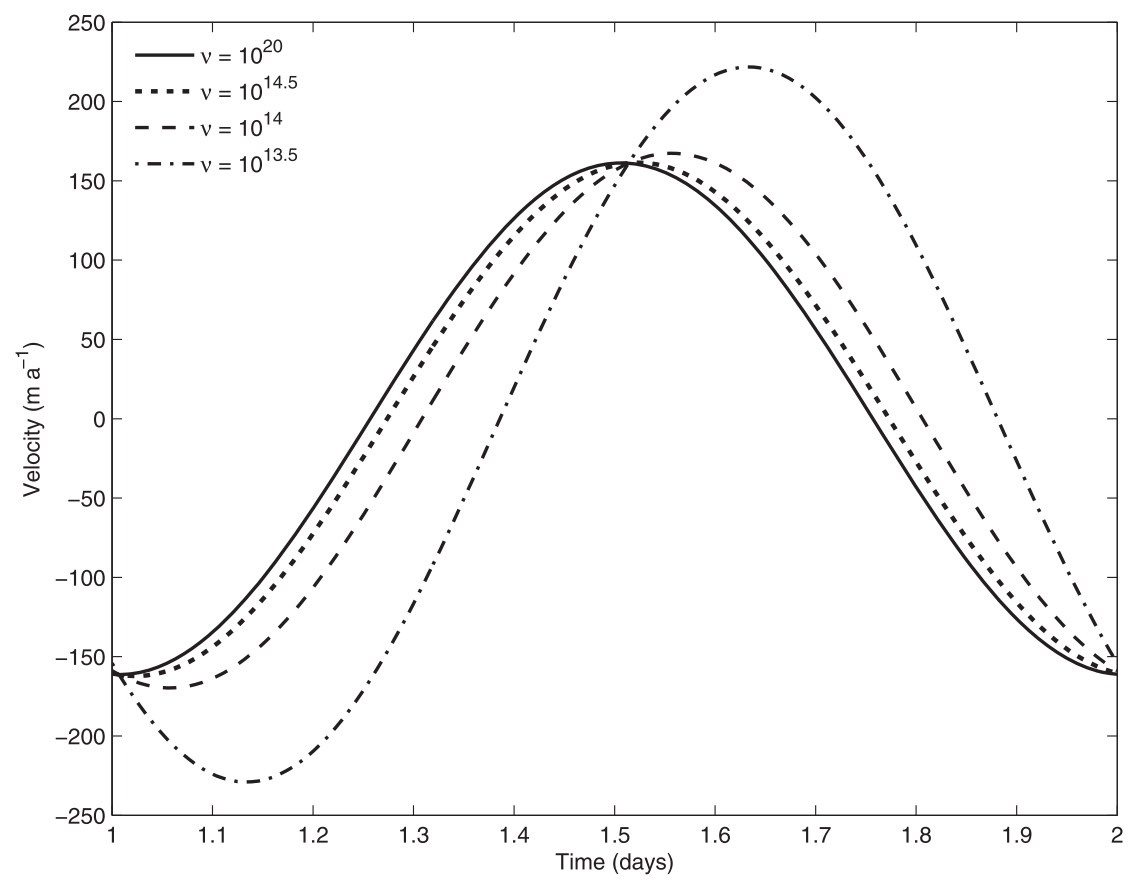

Fig. 3. Perturbation velocity $\tilde{u}$ at grounding line for diurnal tide with perfectly plastic ice-stream bed and various ice viscosities $v$. Velocity for $v=10^{20}$ Pas is identical to the $m=10^{5}$ case in Fig. 1.

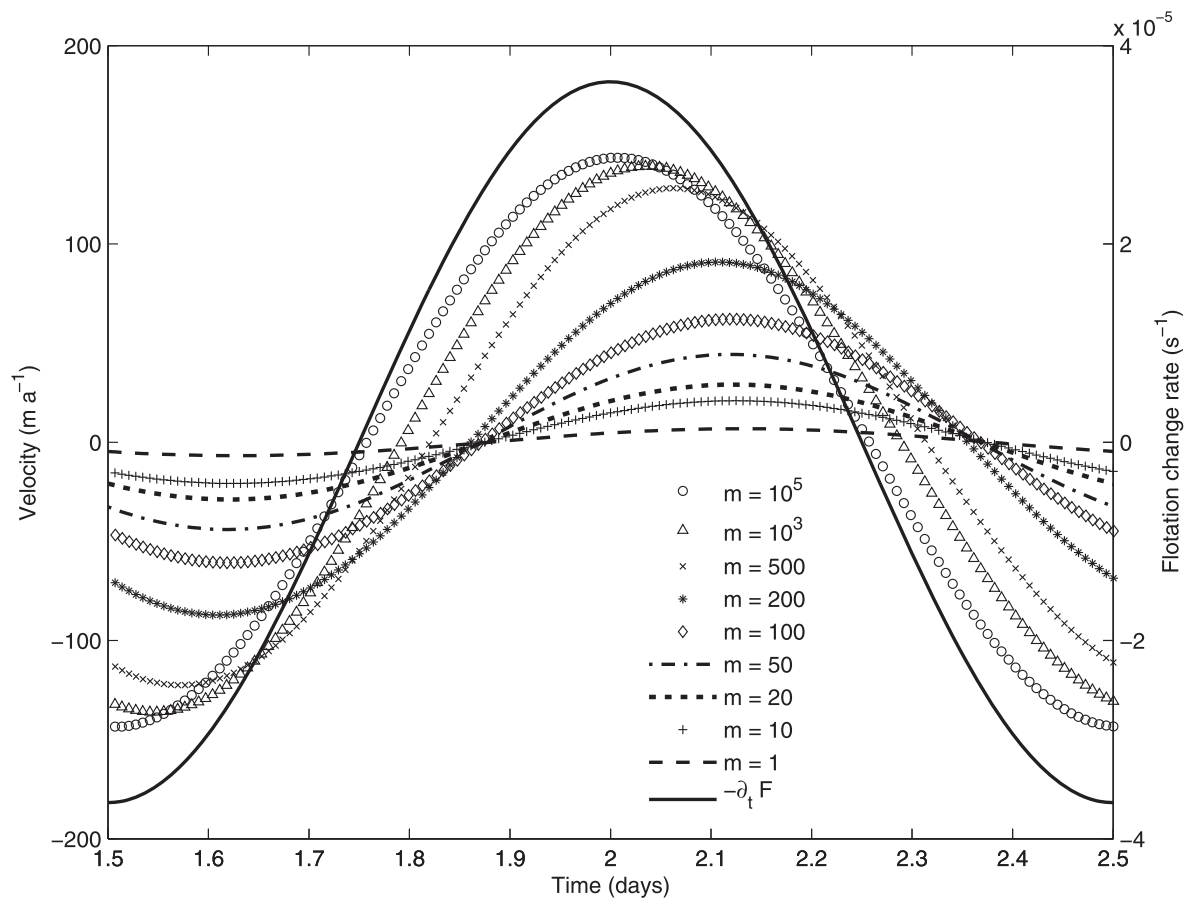

Fig. 4. Perturbation velocity $\tilde{u}$ at grounding line for $\pm 100 \mathrm{~m}$ diurnal grounding-line motion with various ice-stream bed exponents $m$. Negative of the rate of change of grounding-line position $\left(-\partial_{t} \Delta x\right)$, i.e. rate of grounding-line retreat, shown for comparison of timing. Note 0.5 day shift of horizontal axis relative to Fig. 1.

line motion of $\pm 100 \mathrm{~m}$ (half an element) is imposed with the timing of a diurnal tidal cycle. (Although the present model can be parameterized to estimate grounding-line motion, we do not present results here because this process is better handled as a free-boundary problem (Sayag and Worster, 2011, 2013).) Thus, velocity perturbations are driven by the $\partial_{t} \beta^{2}$ term of (7), with the hydrostatic pressure term (9) absent. This forcing is of similar magnitude to the $50 \mathrm{~cm}$ tide of the earlier experiments as the change in horizontally-integrated basal drag is $\tau_{b} \Delta x=$ $20 \mathrm{kPa} \cdot 100 \mathrm{~m}=2 \times 10^{6} \mathrm{Pam}$, while for tide experiments, the change in depth-integrated hydrostatic pressure is approximately $-\rho_{w} g \eta z_{b}=1028 \mathrm{~kg} \mathrm{~m}^{-3} \cdot 9.8 \mathrm{~m} \mathrm{~s}^{-2} \cdot 0.5 \mathrm{~m} \cdot-446 \mathrm{~m} \approx 2.25 \times$ $10^{6} \mathrm{Pam}$. Results, shown in Fig. 4, are very similar to those of the diurnal tide experiments, with velocities proportional to the relative forcing (ratio $\sim 0.89$ ) and identical lags for a given bed exponent $m$. Thus, the dependence of the ice-stream response on bed rheology is identical for the two forcings. It should be noted, however, that the forcings themselves are $12 \mathrm{~h}\left(180^{\circ}\right)$ out of phase and therefore act opposite each other. 


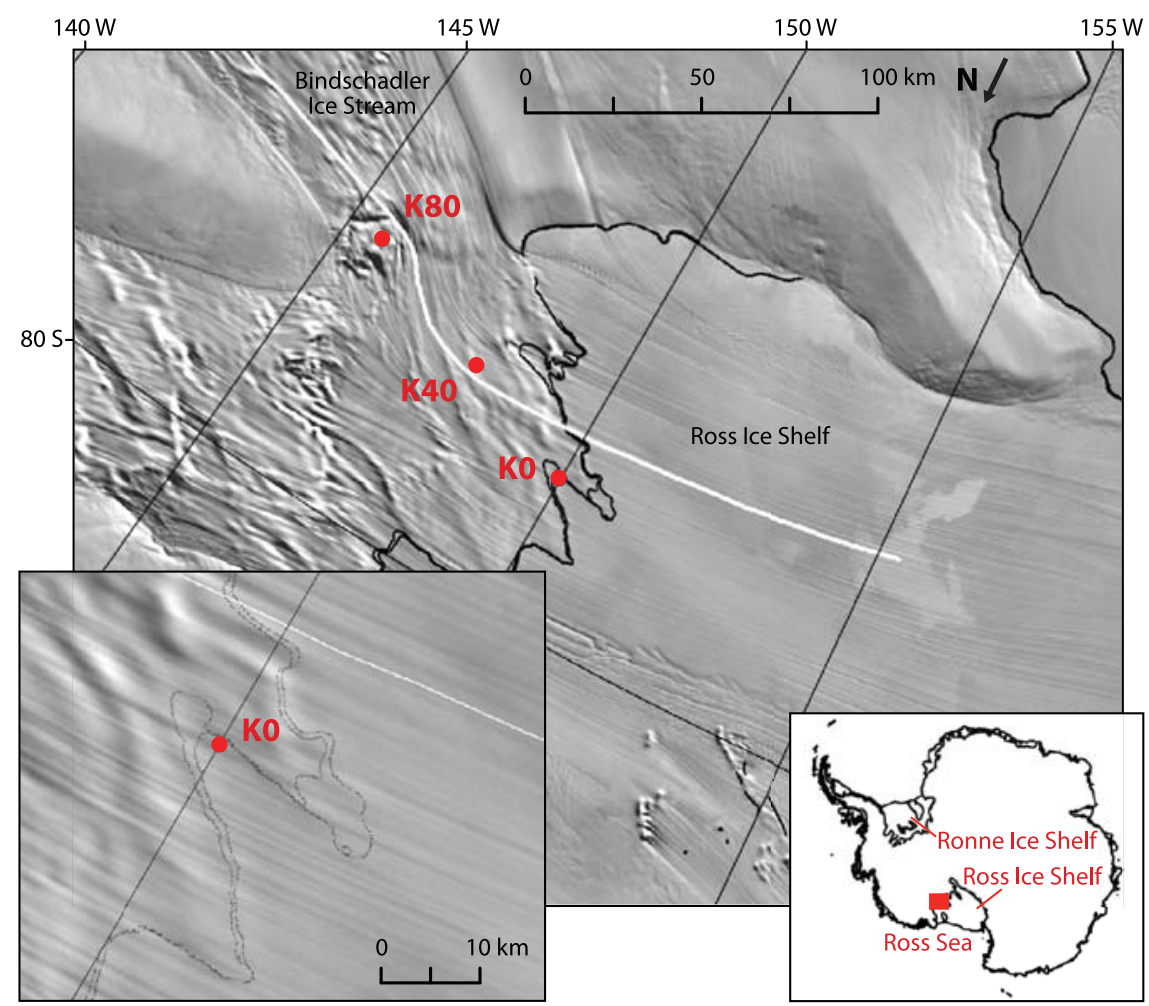

Fig. 5. Bindschadler Ice Stream, showing locations of GPS stations (K0, K40, and K80) used by Anandakrishnan et al. (2003). Ross Ice Shelf grounding zone (Rignot et al., 2011) in black, modeled flowline in white. Image from MODIS Mosaic of Antarctica (Haran et al., 2006).

\section{Application to Bindschadler Ice Stream}

We now apply the model to analyze data collected by Anandakrishnan et al. (2003) on Bindschadler Ice Stream (formerly Ice Stream D), which flows into the Ross Ice Shelf. Kinematic GPS measurements were taken at stations just downstream of the grounding zone (K0), $40 \mathrm{~km}$ inland (K40), and $80 \mathrm{~km}$ inland (K80) that lie near a best-fit flowline (Fig. 5). Analysis of the upstream propagation of tidally driven velocity perturbations by Walker et al. (2012) showed that the bed of this ice stream is effectively plastic (Rathbun et al., 2008), with the exponent $m$ most likely between 8 and 40 . In the present study, we will focus on determining how the observed velocity perturbation in the grounding zone arises from tidal forcing, a question left open by the earlier work.

The grounded section of our flowline is identical to that used by Walker et al. (2012), including flow parameters $\left(\beta^{2}, v\right)$ derived in that study by fitting surface velocity observations. The full flowline eventually makes a sharp northward turn, reaching the ice front just to the west of Roosevelt Island; because our one-dimensional model does not consider lateral drag, we include only the floating section of our flowline that extends essentially straight WNW from the grounding zone. We thus have a $438 \mathrm{~km}$ long flowline consisting of a $288 \mathrm{~km}$ ice stream and a $150 \mathrm{~km}$ ice shelf. Numerical resolution remains the same as for our idealized experiments (200 $\mathrm{m}$ in $x, 10 \mathrm{~min}$ in $t$ ).

Tidal forcing for our model is obtained from the Ross_Inv_2002 regional tidal model (Padman et al., 2003), which has been optimized by assimilating gravimetry-derived tidal constituents on the Ross Ice Shelf. Only the K1 (23.93 h), O1 (25.82 h), M2 (12.42 h), and S2 (12.00 h) constituents are included, because harmonic analysis using the T_ TIDE (version 1.3 beta) program (Pawlowicz et al., 2002) shows that these constituents dominate the velocity perturbations observed at station $\mathrm{KO}$; each has a good signal-to-noise ratio, and our $>11$ day time series meets the Rayleigh criteria for separating constituents close in frequency. Given the strong vertical motion observed by Anandakrishnan et al. (2003), station K0 was certainly floating; however, given its proximity to the grounding zone and its smaller amplitude relative to modeled tidal heights, it was likely not fully hydrostatic. We note that although K0 does not lie perfectly on our flowline ( $\sim 14 \mathrm{~km}$ north), the difference between modeled tides at this station and at the grounding line of our flowline is negligible (a few $\mathrm{mm}$ per constituent). The grounding zone of Bindschadler Ice Stream is expected to have minimal motion based on ICESat repeat-track analysis (Brunt et al., 2010), which suggests that the upstream limit of flexure is constrained to within $500 \mathrm{~m}$ in this area. Therefore, we initially focus on the tides as the sole forcing mechanism.

For all of the runs shown here, we use $E=3.0 \mathrm{GPa}$ and $m=20$. While we do not have enough data to uniquely determine these parameters, this combination produces velocities comparable to observations and has a bed rheology consistent with Walker et al. (2012).

We begin with experiments in which the tide along the entire ice-shelf section of the flowline is assumed to be the same as the tide near the grounding zone. The resulting $\tilde{u}$ at the grounding line is shown in Figs. 6 and 7. As observed by Anandakrishnan et al. (2003), the perturbation velocity reaches its maxima on the falling tide and its minima on the rising tide. Due to varying response times for the tidal constituents, the lag between tidal and velocity extrema (using all four constituents together) has a mean of $6.59 \mathrm{~h}$ and standard deviation of $2.63 \mathrm{~h}$. Observed lags at station $\mathrm{KO}$ (calculated by cross-correlation of the along-flow displacement) were $6 \pm 1 \mathrm{~h}$ (Anandakrishnan et al., 2003), so the model results include the observed range but also some significantly different lags. To investigate this behavior, we consider results for individual tidal constituents. (While the velocity-dependent basal drag makes (11) nonlinear, comparison of results for constituents used individually and in combination shows that the effect is weak enough to allow a term-by-term approach.) Model response to diurnal tides (9.02 h lag for K1, $9.73 \mathrm{~h}$ for 01 ) is noticeably slower than observed 


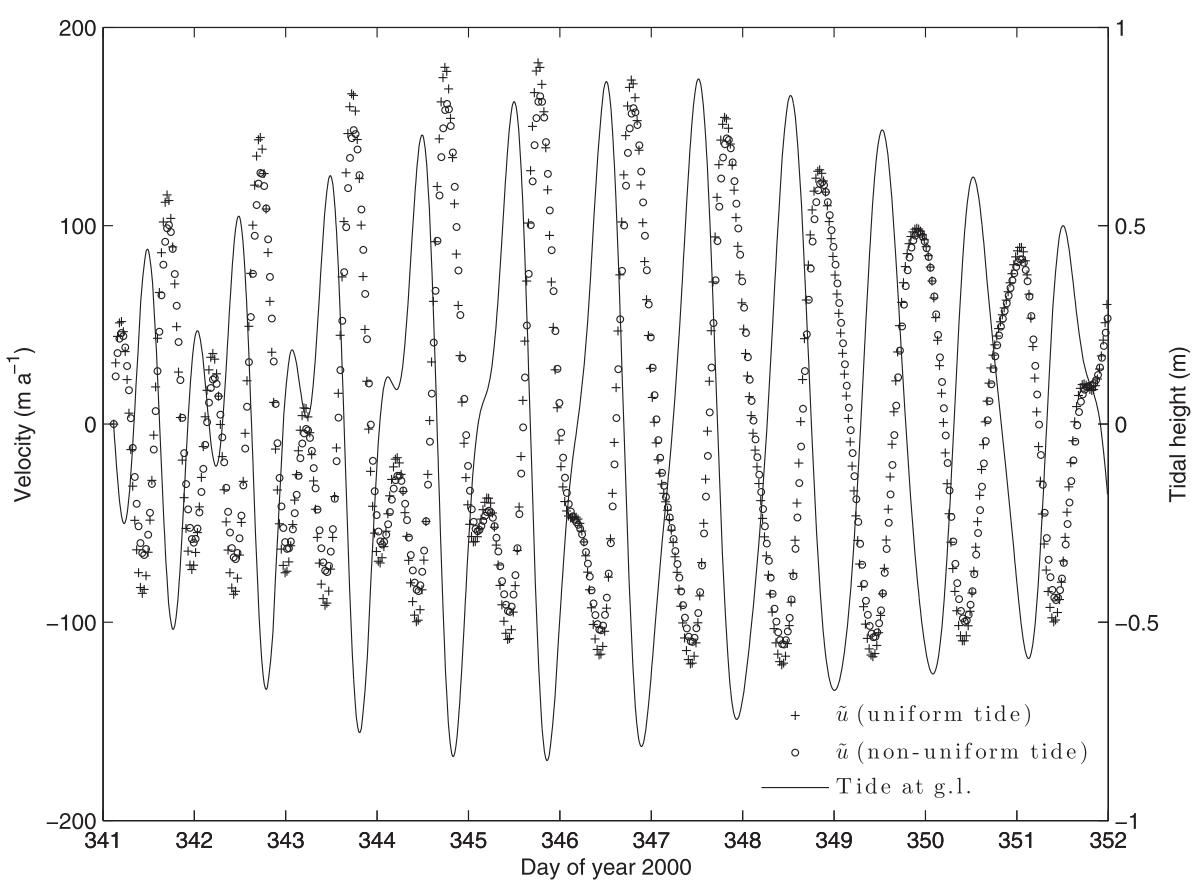

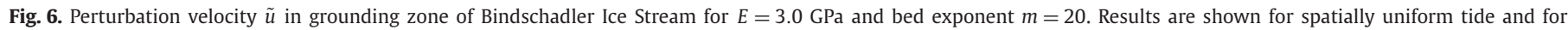
tide varying along the $150 \mathrm{~km}$ floating section of the flowline. Tide $\eta$ shown for comparison of timing. For clarity, only every third point of $\tilde{u}$ is plotted.

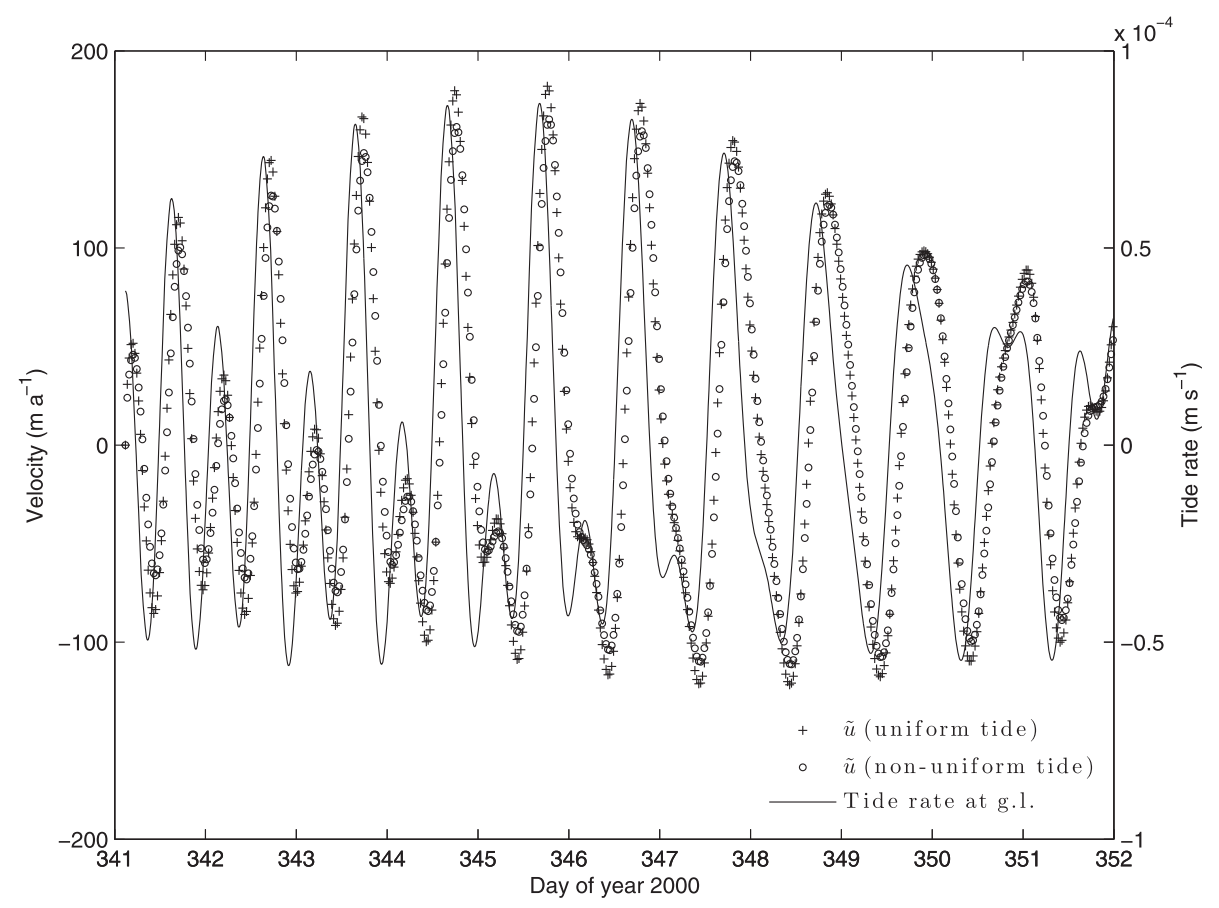

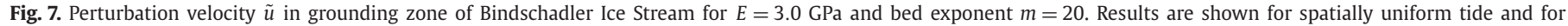

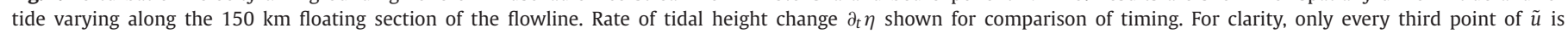
plotted.

( $7.05 \pm 0.18 \mathrm{~h}, 8.39 \pm 0.41 \mathrm{~h}$ respectively, calculated using the $95 \%$ confidence intervals from T_TIDE), but slightly quicker for semidiurnal tides ( $4.71 \mathrm{~h}, 4.87 \mathrm{~h}$ for S2, M2 respectively vs. $5.58 \pm 0.35 \mathrm{~h}$ observed for S2). We note that the lag for the M2 constituent cannot be reliably calculated from the observations because the apparent M2 amplitude of the vertical motion is smaller than the uncertainty of the GPS measurement.

Due to the great size of the Ross Ice Shelf, however, variations in the phase of tidal height across its extent are potentially sig- nificant (e.g., Brunt, 2008). We next run experiments in which the variation of the tide along the ice shelf is considered, so that even the freely floating part of the shelf (where $w=\eta$ ) will have some slope, and the second term of (9) can thus be nonzero over the entire shelf. (While a one-dimensional flowline model cannot fully capture this inherently two-dimensional situation, it is reasonable to expect the along-flow and transverse forcings to be mostly independent when far from lateral boundaries.) Although $\partial_{x} \eta$ is rather small (tidal height difference $<10 \mathrm{~cm}$ over $150 \mathrm{~km}$ ), its effect 


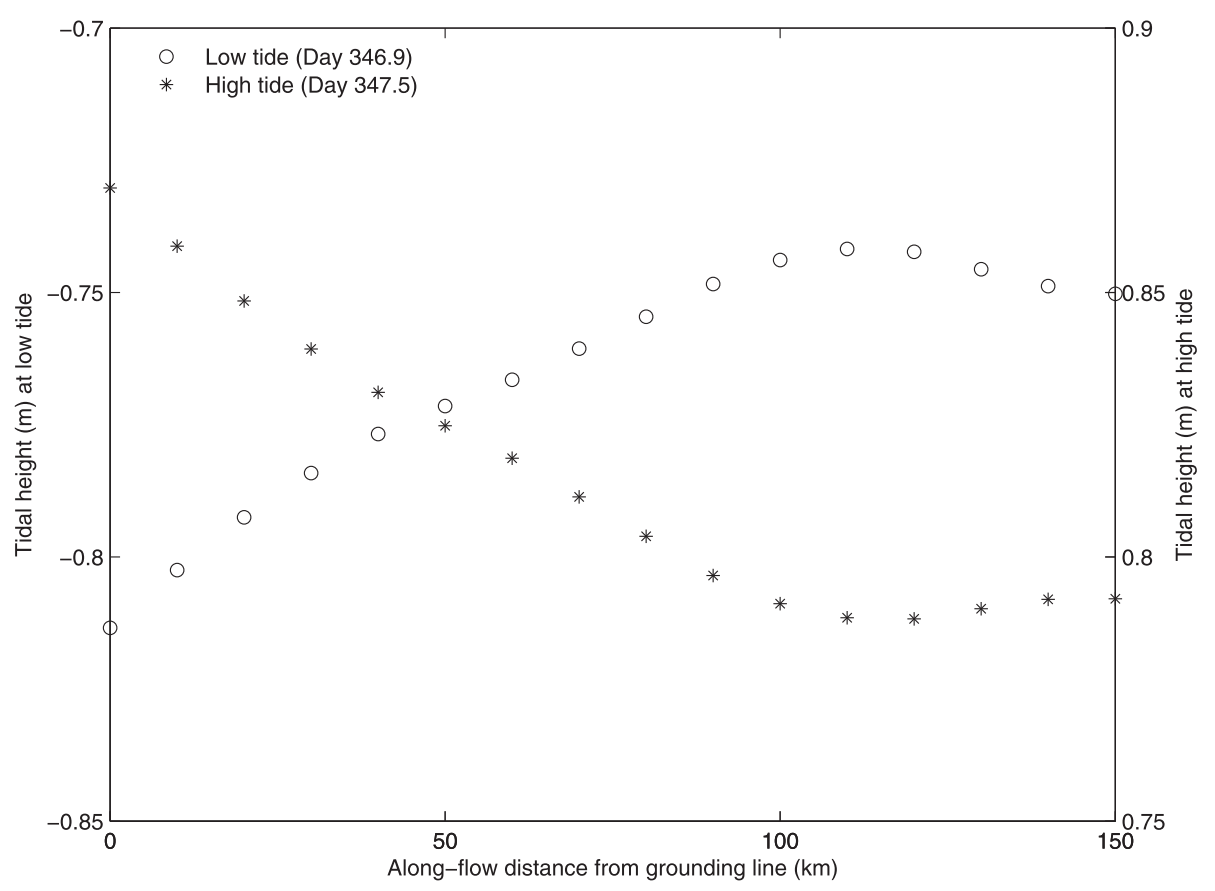

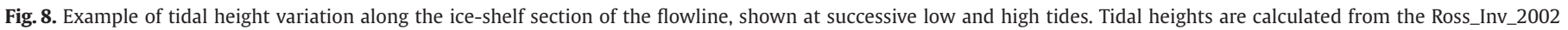
regional tidal model (Padman et al., 2003).

over freely floating ice tends to be directed opposite the effect of the near-grounding-zone tide. That is, most of the shelf slopes downward along flow (leading to a downstream-directed force) when high tide is reached near the grounding zone (an upstreamdirected force), and vice versa (Fig. 8). The result (Figs. 6 and 7) is a reduction in the magnitude of velocity extrema (typically 8-12\%) and additional lag (typically 10-30 min) compared to the uniform-tide run. Separate runs show that the lags increase for each constituent (9.33 h, 10.06 h, 5.25 h, 5.11 h for K1, 01, M2, S2 respectively), leading to a mean overall lag of $7.28 \mathrm{~h}$ with standard deviation $2.95 \mathrm{~h}$, again including the observed range.

The model thus does a reasonably good job of reproducing semidiurnal response, but the diurnal response in the grounding zone of the best-fit flowline is roughly $2 \mathrm{~h}$ later than observed at station K0. As seen in our idealized experiments, reducing the lag by this much would require assuming that the ice-stream bed is highly plastic ( $m \gtrsim 500$ ) for diurnal forcing but has a drastically lower flow exponent for semidiurnal forcing. A frequencydependent flow exponent would be possible if till properties were depth-dependent, as the depth of interaction will be greater for diurnal than for semidiurnal forcing. However, deeper till and/or bedrock would be expected to be less plastic, opposite to the behavior needed to explain the observations. Furthermore, the analysis of upstream propagation of velocity perturbations by Walker et al. (2012) is most consistent with a single flow exponent much lower than would be required to match the lag in diurnal response. It appears more likely that at least one other forcing on a diurnal timescale is present at station $\mathrm{KO}$, and that the timing of the neglected forcing(s) leads to an earlier total response.

It is possible that the diurnal response is affected by the geometry of the grounding zone near station $\mathrm{K} 0$, which is significantly more complex than near the best-fit flowline (Fig. 5). In this region, flowlines (corresponding to streak lines in the MODIS image) are not noticeably influenced by the irregularities of the grounding zone, suggesting that the bed is not locally strong enough to affect the direction of the mean flow. The streak line through K0 does not run seaward along the inlet; instead, it regrounds downstream of the station, and passes through areas of significant ephemeral grounding both upstream and downstream.

Anandakrishnan et al. (2003) observed significant tidally driven motion of station $\mathrm{K} 0$ transverse to the mean flow of the ice stream, speculating that this cross-line perturbation was due to the same shelf tilt that we consider only in the along-flow direction. We perform tidal analysis of these GPS velocities at K0 using T_TIDE. While GPS-related systematic errors associated with the K1 and S2 constituents probably exist, we assume that they are generally small $(<3 \mathrm{~mm})$ based on King et al. $(2008,2011)$. Our results indicate a complicated two-dimensional velocity vector composed of ellipses associated with the tidal constituents (Fig. 9), with a strong tendency for the velocity perturbation to be aligned with the inlet or the upstream area of ephemeral grounding rather than with the flowline. The complexity of this forcing, which may involve the entire shelf, could in itself lead to results that cannot be predicted by a one-dimensional model. Furthermore, this combination of offaxis forcing and ephemeral grounding should lead to constantly shifting patterns of basal drag along the direction of the perturbation and thus affect the timing of the response at station K0. Yet another possibility is that flexure-driven pressure changes at the bed (Walker et al., 2013) cause subglacial water flow and/or till deformation that could also produce fluctuations in basal drag.

For a given tidal constituent, any process affecting basal drag would likely result in time dependence of the lag and/or of the amplitude of the velocity perturbation. However, harmonic analysis programs like T_TIDE seek constant-amplitude sinusoidal signals at known tidal frequencies, so that any modulation of the grounding-line response (in frequency or amplitude) present in the data would be averaged out in the fitting process. Detection of grounding-zone basal drag effects may then depend on other signal-processing techniques like bandpass filtering; unfortunately, the current time series does not have sufficient length or resolution to produce unambiguous results. Further investigation will require a two-dimensional model, along with more detailed observations of the relative timing of tides and ephemeral grounding throughout the grounding zone. 

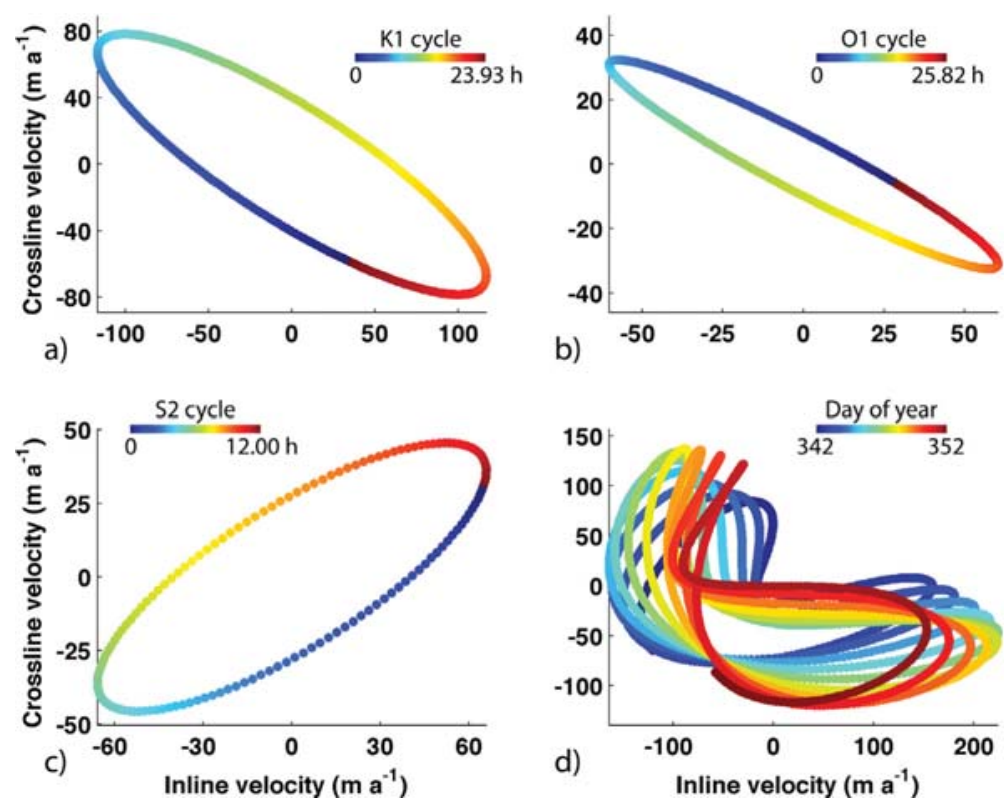

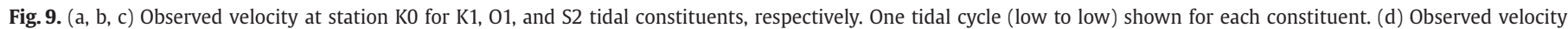
at station K0 for K1, 01, and S2 tidal constituents combined. Days 342 to 352 of year 2000 shown. Velocity vector follows path in a generally clockwise direction.

\section{Conclusions}

Understanding the mechanisms by which vertical flexure of ice shelves induces horizontal motion of ice streams will likely lead to improved understanding of ice-stream dynamics. Our viscoelastic coupled flexure-flowline model shows that over the full range of bed exponents, the magnitude and timing of ice-stream response to tidal forcing depend strongly on the basal sliding law, although there is a range of realistic, effectively plastic bed exponents for which timing is nearly independent of rheology. Because we consider primarily diurnal and semidiurnal timescales, the elastic component of the response dominates, so that the ice stream responds to the rate of applied stress (with some delay as the sliding law departs from perfect plasticity). Applying this model to Bindschadler Ice Stream, we obtain reasonable agreement with observations of highest velocity during the falling tide and lowest velocity during the rising tide. More precise matching of observed velocities will require both a higher-dimensional model and detailed observations of ephemeral grounding throughout the geometrically complex grounding zone.

\section{Acknowledgements}

This research was supported by NSF under grants 0424589 (R.B.A., B.R.P.), 1338832 (R.B.A., B.R.P.), and 0944286 (R.B.A.), and by NASA under grants NNX10AI04G (R.B.A., B.R.P., R.T.W.), NNX12AD03A (R.T.W.), NNX12AP50G (R.T.W.), and the NASA Science Innovation Fund (K.M.B.).

\section{References}

Anandakrishnan, S., Alley, R.B., 1997. Tidal forcing of basal seismicity of ice stream C, West Antarctica, observed far inland. J. Geophys. Res. 102 (B7), 15183-15196.

Anandakrishnan, S., Voigt, D.E., Alley, R.B., King, M.A., 2003. Ice stream D flow speed is strongly modulated by the tide beneath the Ross Ice Shelf. Geophys. Res. Lett. 30 (7), 1361. http://dx.doi.org/10.1029/2002GL016329.

Bindschadler, R., Choi, H., Wichlacz, A., Bingham, R., Bohlander, J., Brunt, K., Corr, H., Drews, R., Fricker, H., Hall, M., Hindmarsh, R., Kohler, J., Padman, L., Rack, W., Rotschky, G., Urbini, S., Vornberger, P., Young, N., 2011. Getting around Antarctica: new high-resolution mappings of the grounded and freely-floating boundaries of the Antarctic ice sheet created for the International Polar Year. The Cryosphere 5, 569-588. http://dx.doi.org/10.5194/tc-5-569-2011.
Bindschadler, R.A., King, M.A., Alley, R.B., Anandakrishnan, S., Padman, L., 2003. Tidally controlled stick-slip discharge of a West Antarctic ice stream. Science 301 (5636), 1087-1089.

Brunt, K.M., 2008. Tidal motion of the Ross Ice Shelf and its interaction with the Siple Coast Ice Streams, Antarctica. PhD thesis. University of Chicago.

Brunt, K.M., Fricker, H.A., Padman, L., 2011. Analysis of ice plains of the FilchnerRonne Ice Shelf, Antarctica, using ICESat laser altimetry. J. Glaciol. 57, 965-975.

Brunt, K.M., Fricker, H.A., Padman, L., Scambos, T.A., O'Neel, S., 2010. Mapping the grounding zone of the Ross Ice Shelf, Antarctica, using ICESat laser altimetry. Ann. Glaciol. 51 (55), 71-79.

Christianson, K., Parizek, B.R., Alley, R.B., Horgan, H.J., Jacobel, R.W., Anandakrishnan, S., Keisling, B.A., Craig, B.D., 2013. Ice sheet grounding zone stabilization due to till compaction. Geophys. Res. Lett. 40, 1-6. http://dx.doi.org/10.1002/ 2013 GL057447.

Dupont, T.K., Alley, R.B., 2005. Assessment of the importance of ice-shelf buttressing to ice-sheet flow. Geophys. Res. Lett. 32, L04503. http://dx.doi.org/10.1029/ 2004 GL022024.

Fricker, H.A., Coleman, R., Padman, L., Scambos, T.A., Bohlander, J., Brunt, K.M., 2009. Mapping the grounding zone of the Amery Ice Shelf, East Antarctica using InSAR, MODIS and ICESat. Antarct. Sci. 21 (5), 515-532.

Gudmundsson, G.H., 2006. Fortnightly variations in the flow velocity of Rutford Ice Stream, West Antarctica. Nature 444, 1063-1064. http://dx.doi.org/10.1038/ nature 05430 .

Gudmundsson, G.H., 2007. Tides and the flow of Rutford Ice Stream, West Antarctica. J. Geophys. Res. 112, F04007. http://dx.doi.org/10.1029/2006JF000731.

Gudmundsson, G.H., 2011. Ice-stream response to ocean tides and the form of the basal sliding law. The Cryosphere 5, 259-270. http://dx.doi.org/10.5194/ tc-5-259-2011.

Haran, T., Bohlander, J., Scambos, T., Painter, T., Fahnestock, M., Compilers (2005, updated 2006), MODIS mosaic of Antarctica (MOA) image map. Boulder, Colorado USA: National Snow and Ice Data Center, Digital media.

Holdsworth, G., 1969. Flexure of a floating ice tongue. J. Glaciol. 8, 385-397.

Holdsworth, G., 1977. Tidal interaction with ice shelves. Ann. Geophys. 33, 133-146.

Holland, P.R., Jenkins, A., Holland, D.M., 2008. The response of ice shelf basal melting to variations in ocean temperature. J. Climate 21, 2558-2572. http://dx.doi.org/ 10.1175/2007JCLI1909.1.

King, M.A., Murray, T., Smith, A.M., 2010. Non-linear responses of Rutford Ice Stream, Antarctica, to semi-diurnal and diurnal tidal forcing. J. Glaciol. 56, 167-176.

King, M.A., Padman, L., Nicholls, K., Clarke, P.J., Gudmundsson, G.H., Kulessa, B., Shepherd, A., 2011. Ocean tides in the Weddell Sea: new observations on the Filchner-Ronne and Larsen C ice shelves and model validation. J. Geophys. Res. 116, C06006. http://dx.doi.org/10.1029/2011JC006949.

King, M.A., Watson, C.S., Penna, N.T., Clarke, P.J., 2008. Subdaily signals in GPS observations and their effect at semiannual and annual periods. Geophys. Res. Lett. 35, L03302. http://dx.doi.org/10.1029/2007GL032252.

Lingle, C.S., Hughes, T.J., Kollmeyer, R.C., 1981. Tidal flexure of Jakobshavns Glacier, West Greenland. J. Geophys. Res. 86, 3960-3968.

Murray, T., Smith, A.M., King, M.A., Weedon, G.P., 2007. Ice flow modulated by tides at up to annual periods at Rutford Ice Stream, West Antarctica. Geophys. Res. Lett. 34 (18), L18503. http://dx.doi.org/10.1029/2007GL031207. 
Padman, L., Erofeeva, S., Joughin, I., 2003. Tides of the Ross Sea and Ross Ice Shelf Cavity. Antarct. Sci. 15 (01), 31-40.

Pawlowicz, R., Beardsley, B., Lentz, S., 2002. Classical tidal harmonic analysis including error estimates in MATLAB using T_TIDE. Comput. Geosci. 28, 929-937.

Rathbun, A.P., Marone, C., Alley, R.B., Anandakrishnan, S., 2008. Laboratory study of the frictional rheology of sheared till. J. Geophys. Res. 113, F02020. http://dx.doi.org/10.1029/2007JF000815.

Reeh, N., Christensen, E.L., Mayer, C., Olesen, O.B., 2003. Tidal bending of glaciers: a linear viscoelastic approach. Ann. Glaciol. 37, 83-89.

Rignot, E., Mouginot, J., Scheuchl, B., 2011. Antarctic grounding line mapping from differential satellite radar interferometry. Geophys. Res. Lett. 38, L10504 http://dx.doi.org/10.1029/2011GL047109.

Robin, G. de Q 1958. Glaciology III. Seismic shooting and related investigations. In: Norwegian-British-Swedish Antarctic Expedition, 1949-1952, Scientific Results, vol. V. Norsk Polarinstitut.

Sayag, R., Worster, M.G., 2011. Elastic response of a grounded ice sheet coupled to a floating ice shelf. Phys. Rev. E 84, 036111. http://dx.doi.org/10.1103/ PhysRevE.84.036111.

Sayag, R., Worster, M.G., 2013. Tidal migration of ice-sheet grounding lines modifies sub-glacial lubrication and melting. Geophys. Res. Lett 40 (22), 5877-5881. http://dx.doi.org/10.1002/2013GL057942.

Scambos, T.A., Haran, T.M., Fahnestock, M.A., Painter, T.H., Bohlander, J., 2007. MODIS-based mosaic of Antarctica (MOA) data sets: continent-wide surface morphology and snow grain size. Remote Sens. Environ. 111 (2-3), 242-257. http://dx.doi.org/10.1016/j.rse.2006.12.020.

Schmeltz, M., Rignot, E., MacAyeal, D., 2002. Tidal flexure along ice-sheet margins: comparison of InSAR with an elastic-plate model. Ann. Glaciol. 34, 202-208.

Sergienko, O.V., 2010. Elastic response of floating glacier ice to impact of longperiod ocean waves. J. Geophys. Res. 115, F04028. http://dx.doi.org/10.1029/ 2010JF001721.

Tulaczyk, S., 2006. Scale independence of till rheology. J. Glaciol. 52 (178), 377-380. Turcotte, D.L., Schubert, G., 2002. Geodynamics, 2nd ed. Cambridge.

Walker, R.T., Christianson, K., Parizek, B.R., Anandakrishnan, S., Alley, R.B., 2012. A viscoelastic flowline model applied to tidal forcing of Bindschadler Ice Stream, West Antarctica. Earth Planet. Sci. Lett. 319-320, 128-132. http://dx.doi.org/ 10.1016/j.epsl.2011.12.019.

Walker, R.T., Parizek, B.R., Alley, R.B., Anandakrishnan, S., Riverman, K.L., Christianson, K., 2013. Ice-shelf tidal flexure and subglacial pressure variations. Earth Planet. Sci. Lett. 361, 422-428. http://dx.doi.org/10.1016/j.epsl.2012.11.008.

Winberry, J.P., Anandakrishnan, S., Alley, R.B., Bindschadler, R.A., King, M.A., 2009. Basal mechanics of ice streams: insights from the stick-slip motion of Whillans Ice Stream, West Antarctica. J. Geophys. Res. 114, F01016. http://dx.doi.org/ 10.1029/2008JF001035.

Winberry, J.P., Anandakrishnan, S., Wiens, D.A., Alley, R.B., Christianson, K., 2011. Dynamics of stick-slip motion, Whillans Ice Stream, Antarctica. Earth Planet Sci. Lett. 305, 283-289. http://dx.doi.org/10.1016/j.epsl.2011.02.052. 